\title{
Gestão estratégica do desenvolvimento endógeno: crescimento auto-sustentado exige novos investimentos
}

Strategic administration of the inside development: self-sustained grouth demands new investments

\author{
Gestion stratégique du développement endogène : croissance auto-souténi exige \\ nouveaux investissements \\ Gestión Estratégica del Desarrollo Endógeno: crecimiento auto sustentado exige nuevas \\ inversiones
}

\author{
Nilson Araújo de Souza*
}

Recebido em 2/3/2006; revisado e aprovado em 30/3/2006; aceito em 30/7/2006. Resumo: O objetivo deste artigo é examinar as condições necessárias ao crescimento econômico auto-sustentado,
tomando como base de análise o comportamento recente da economia brasileira. Partimos da premissa de que,
reiniciada a reanimação da economia por ocupação de capacidade ociosa, a continuidade do crescimento da produção
numa economia como a nossa passa a depender do aumento da sua capacidade produtiva, o que exige novos investimentos.

Palavras-chave: Gestão estratégica; desenvolvimento endógeno; crescimento auto-sustentado.

Abstract: The objective of this article is to examine the essential conditions to continual economic growth. The support of this analyses is the recent evolution of the brazilian economy. Our premise is the following: after de economy becomes reanimated using inactive capacity, the continuation of the production growth in a economy like ours depends on the increasing of its productive capacity, which demands new investments.

Key words: Strategic administration; independent development; continual growth.

Résumé: L'objectif de cet article est d'examiner les conditions nécessaires à la croissance économique durable, prenant comme base d'analyse le comportement récent de l'économie brésilienne. A partir de la prémisse de ce que, la reprise de l'économie par l'occupation de la capacité oisive, la continuité de la croissance de la production dans une économie, comme la nôtre, passe à dépendre de l'augmentation de sa capacité productive, ce qui exige de nouveaux investissements.

Mots-clé: Gestion stratégique; développement endogène; croissance auto-soutenue.

Resumen: El objetivo de este artículo es examinar las condiciones necesarias para el crecimiento económico autosustentable, tomando como base de análisis el comportamiento reciente de la economía brasilera. Partimos de la base de que, reiniciado el rejuvenecimiento de la economía por ocupación de capacidad ociosa, la continuidad del crecimiento de la producción en una economía como la nuestra, pasa a depender del aumento de su capacidad productiva, lo que exige nuevas inversiones.

Palabras clave: Gestión estratégica; desarrollo endógeno; crecimiento autosustentable.

\section{Introdução}

O objetivo deste artigo é examinar as condições necessárias ao crescimento econômico auto-sustentado, tomando como base de análise o comportamento recente da economia brasileira. Partimos da premissa de que, havendo a reanimação da economia reiniciado ao final de 2003 por ocupação de capacidade ociosa, a continuidade do crescimento da produção passa a depender do aumento da sua capacidade produtiva, o que exige novos investimentos.
A capacidade ociosa havia sido produzida no triênio anterior, quando a economia atravessou um período de semi-estagnação: o PIB crescera a uma taxa média anual em torno de $0,7 \%$. Assim, de acordo com levantamento da Confederação Nacional da Indústria, as empresas industriais apresentaram um índice médio de capacidade ociosa de $29,5 \%$ ao longo de 2003; a Sondagem da Indústria de Transformação da FGV, usando outra metodologia, revelou um índice de $20 \%$. No último trimestre de 2004, depois de cerca de um ano de expansão do

\footnotetext{
* Doutor em Economia pela Universidad Nacional Autónoma de Mexico (UNAM), com Pós-Doutoramento na USP; professor-pesquisador do Programa de Pós-Graduação da Universidade Ibirapuera (UNIb); autor de vários livros sobre Teoria Econômica, Economia Mundial e Economia Brasileira. Seu mais recente livro é A longa agonia da dependência - economia brasileira contemporânea (JK/FH), editado em 2004 pela Alfa-Omega. (araujonilson@terra.com.br).
} 
PIB a uma taxa média anual em torno de $5 \%$, a ociosidade industrial ainda permanecia elevada: $23 \%$ pela pesquisa da CNI.

Num primeiro momento, diante da existência de capacidade ociosa, a produção pode crescer em resposta a impulsos provocados pelo crescimento da demanda, interna ou externa. No entanto, esgotada a ociosidade, o incremento da capacidade produtiva, produzida pela melhoria do nível de investimento, passa a ser a variável chave para a continuidade do crescimento, isto é, para transformar a reanimação da economia em crescimento auto-sustentado. E vamos demonstrar que a taxa de juros é o instrumento decisivo nesse processo.

\section{Poupança é drenada para o exterior ou para a especulação financeira}

Vejamos primeiro como se dá o aumento da capacidade produtiva da economia, isto é, a realização de novos investimentos. No caso do Brasil, apesar de havermos entrado em 2005 no segundo ano de recuperação econômica, os investimentos ainda não reagiram na proporção necessária. A taxa de investimento, medida pela relação entre a formação bruta de capital fixo e o PIB, que baixara de 18,33\% em 2002 para $18,05 \%$ em 2003, subiu para apenas $18,95 \%$ no primeiro semestre de 2004 (IBGE) e para $19,6 \%$ na média do ano, taxa semelhante à que vigorou durante os dois mandatos de estagnação econômica de Fernando Henrique $(19,4 \%)$, conforme se pode verificar pela tabela ao final do texto (IBGE; Folha Online Dinheiro, 2005a).

É importante registrar que, em 2004, a taxa de poupança foi de 23,2\% (Folha Online Dinheiro, 2005a) ${ }^{1}$. Ou seja, um volume de poupança correspondente a $3,6 \%$ do PIB não foi canalizado para o investimento. Para onde foi drenado esse enorme volume de recursos, equivalente a R \$ 63,75 bilhões (Folha Online Dinheiro, 2005a e b) ${ }^{2}$ ? Simples: para o exterior, a fim de remunerar o capital estrangeiro aqui aplicado, em suas várias modalidades. Se não estivéssemos sofrendo essa hemorragia externa, poderíamos ter investido $23,2 \%$ do PIB, cifra próxima à que vigorou na década de 1970, quando nosso PIB cresceu a uma taxa média anual de 9\% (IBGE) 3 .
Outra parcela importante da renda nacional, que às vezes nem chega a converterse em poupança, é esterilizada na especulação financeira, desviando-se, assim, do investimento produtivo. A transferência desses recursos para o setor financeiro pode ocorrer de duas formas: 1) de forma direta, quando o setor produtivo, sobrecarregado de juros, paga pesados encargos financeiros ao sistema financeiro; 2) de forma indireta, quando o setor produtivo, sobrecarregado de tributos, transfere renda ao setor público, o qual, por sua vez, sobrecarregado de juros, gera um enorme superávit primário a fim de repassar parcela dessa renda ao sistema financeiro. É por isso que a lucratividade dos bancos vem sendo sempre muito superior à lucratividade das empresas industriais e comerciais ("Melhores e maiores", Revista Exame, 1999, p.12; 2003, p.22) ${ }^{4}$, e boa parte desses ganhos dos bancos circula apenas na esfera financeira, nunca retornando à área produtiva. Sob o peso dos encargos financeiros alavancados pelos juros estratosféricos, nem as empresas produtivas (SOUZA, 2004, p.699-700) ${ }^{5}$ nem o Estado conseguem realizar um nível de investimento capaz de viabilizar o crescimento auto-sustentado da economia.

Os dirigentes do IBGE, depois de divulgarem as informações sobre o crescimento industrial de 2004, procuraram nos convencer de que o investimento estaria tendo um importante crescimento, na medida em que a produção do setor de bens de capital (que produz bens destinados a aumentar a capacidade produtiva) teve um aumento de $19,7 \%$ no ano. Mas a própria nota do IBGE mata a charada: as exportações desse setor aumentaram 54\% (IBGE, 2005, p.2). Ou seja, a principal parte do aumento da produção de bens de capital não se destinou ao sustento do investimento interno, mas ao mercado externo.

Fica claro, assim, que a garantia desse nível de investimento depende da limitação da drenagem dos recursos para o exterior e para a especulação financeira. Isso implica em três ordens de medidas: 1) reduzir substancialmente o uso do superávit da balança comercial na cobertura da amortização de dívida externa e dos encargos do passivo externo; 2) reduzir fortemente a taxa básica real de juros; 3) reduzir de forma semelhante 
o superávit primário das contas públicas. Não apenas uma maior parcela da renda nacional seria destinada à poupança, como esta, ao invés de ser drenada para o exterior ou esterilizada na especulação financeira, seria convertida em investimento. Os saldos comerciais poderiam ser usados, em grande medida, para adquirir no exterior equipamentos ou tecnologias dos quais não houvesse disponibilidade interna; além disso, ajudariam a formar as reservas cambiais indispensáveis à diminuição da nossa vulnerabilidade externa. A parcela economizada do superávit primário se converteria em poupança real (em lugar de mera poupança financeira, nas mãos dos especuladores) e seria canalizada para o investimento produtivo. A queda dos juros, além de viabilizar essa conversão de superávit primário em poupança e investimento, diminui os encargos financeiros das empresas, aumentando também sua capacidade de investimento; ademais, tende a estimular a tomada de dinheiro emprestado para investir e a desestimular o uso dos recursos próprios para aplicações financeiras, canalizando-os para o investimento.

\section{Autoridades monetárias são viciadas em juros altos}

Como, então, derrubar os juros? As autoridades monetárias alegam que eles têm que continuar elevados para promover a convergência da inflação para a meta estabelecida e para garantir o refinanciamento da dívida pública. Ora, como o Conselho Monetário Nacional (CMN) tem fixado metas inflacionárias declinantes e como as autoridades do BC racionalizam que inflação se derruba com juros elevados, a postura de buscar fazer a inflação efetiva convergir para a meta exigiria juros reais sempre elevados ou mesmo em elevação. Isso significa que o sistema de metas de inflação é incompatível com a queda efetiva e sustentada da taxa de juros enquanto as metas forem declinantes.

No entanto, se a diretoria do BC fosse menos dogmática no manuseio desse sistema, e recorresse a uma brecha estabelecida por ele próprio, que é o uso da margem que a taxa de inflação pode atingir, em torno do núcleo da meta, haveria espaço para a queda dos juros, mesmo dentro do sistema. No caso do Brasil, a margem acordada é de 2,5 pontos percentuais. Assim, para 2004, como a meta estabelecida era de $5,5 \%$, a taxa poderia atingir $8 \%$ (ficou em 7,6\%); para 2005, como a meta original de $4,5 \%$ foi alterada para $5,1 \%$, a taxa poderia atingir os mesmos $7,6 \%$ a que chegou em 2004; para 2006, como a meta é de $3,5 \%$, a taxa poderá atingir $6 \%$. Bastaria lidar com essa flexibilidade que o próprio sistema de metas permite para ter uma postura menos rígida em relação à política monetária, mas o fundamentalismo da equipe do Banco Central que aí está impede esse comportamento. Além disso, como a taxa de inflação vem caindo ${ }^{6}$, até mesmo um monetarista mais dogmático, mas que não seja inteiramente comprometido com o sistema financeiro, tenderia a baixar a taxa real de juros ${ }^{7}$. Portanto, mesmo para um monetarista, que acredita que inflação se combate com juros altos, não há fundamento em manter a taxa selic nos níveis atuais e muito menos, em elevá-la, como ocorreu de setembro de 2004 a agosto de 2005 .

Não foi à toa que os tecnocratas do BC escolheram o sistema de "metas de inflação", além de praticá-lo de maneira tão rígida. É que esse é o sistema de "combate" à inflação que mais aproveita aos banqueiros e demais rentistas que especulam com a dívida públi$\mathrm{ca}$, aos quais se sentem ligados. Registre-se que, costumeiramente, no Brasil, os dirigentes do Banco Central têm vínculos com a área financeira (ou são oriundos dos bancos ou para lá vão depois de concluído seu tempo à frente do BC), mas, no passado, esse vínculo se dava sobretudo com os bancos privados nacionais (BAPTISTA JR., 2005). No entanto, desde que Pedro Malan foi presidente do BC, na época em que Fernando Henrique era ministro da Fazenda, inaugurou-se uma época em que os presidentes desse banco têm sido vinculados ao sistema financeiro internacional: o próprio Malan foi diretor do BIRD e do BID, Armínio Fraga foi o principal operador do mega-especulador George Soros e Henrique Meirelles foi presidente mundial do BankBoston, de onde recebe a miserável aposentadoria de US\$ 750 mil por ano.

$\mathrm{O}$ outro argumento alegado pela tecnocracia do Banco Central é o de que a baixa dos juros dificultaria o refinanciamento da dívida pública. Antes, quando havia défi- 
cit comercial e na conta corrente do balanço de pagamentos, o argumento era o de que havia necessidade de atrair capitais externos para cobri-lo; agora, quando o déficit desapareceu e converteu-se em superávit, diz-se que a questão é o refinanciamento da dívida pública. Ora, mesmo admitindo que fosse necessário, para esse refinanciamento, o aporte de capitais externos ou de capitais internos que podem se evadir, a situação atual do mercado financeiro internacional propicia uma ampla folga para a queda dos juros no Brasil. Vejamos as razões: 1) os enormes déficits gêmeos dos EUA vêm gerando certa insegurança dos aplicadores internacionais em destinar seus recursos àquele país, aumentando, assim, a liquidez internacional; 2) o excesso de dinheiro disponível para aplicação tem provocado, em conseqüência, a manutenção dos juros reais em níveis muito baixos nas várias praças do planeta, sendo negativos na União Européia e no Japão; 3) o critério adotado pelos especuladores internacionais para aplicar seu dinheiro em determinado país, que soma a taxa básica dos EUA, o chamado risco-País e a correção cambial, formaria uma taxa básica em torno de $7 \%$ no Brasil. Não bastasse isso, a taxa básica real de juros no Brasil é cerca de três vezes maior do que a segunda colocada, sete vez maior do que a vigente nos chamados países emergentes e dez vezes maior do que a média mundial. Há, portanto, uma enorme folga para sua derrubada.

Assim, mesmo dentro da lógica neoliberal-monetarista, que usa como pretexto para uma política monetária apertada o sistema de "metas de inflação" e a necessidade de refinanciamento da dívida pública - o que leva a formar a taxa de juros interna com base nos critérios dos especuladores internacionais, isto é, com base nos interesses da banca internacional, e não nas necessidades internas do País -, há muito espaço para a queda dos juros no Brasil. Há, portanto, outra causa para a insistência dogmática em manter os juros elevados: a submissão dos dirigentes do Banco Central - senão comprometimento direto ${ }^{8}$ - à ação monopólica dos cartéis financeiros, sobretudo os estrangeiros ${ }^{9}$.

O próprio processo através do qual é estabelecida mensalmente a taxa selic revela essa verdade. Um dos principais instru- mentos, senão o principal, que fundamentam a decisão do Comitê de Política Monetária do Banco (COPOM) é a "pesquisa Focus", que é feita semanalmente junto a pouco mais de 100 executivos de instituições financeiras, mas termina, na verdade, predominando a resposta dos 10 maiores bancos instalados no País. Ali, dentre outras coisas, eles dizem quais são suas "expectativas" - isto é, seu desejo ou especulação - sobre os juros e a inflação futuros. E a tendência do COPOM vem sendo "adotar" as taxas resultantes dessa "pesquisa", sancionando, assim, as supostas expectativas dos agentes financeiros. Como, na verdade, não se trata de expectativas, mas de desejo ou especulação, a tendência deles, obviamente, é puxar para cima as "expectativas inflacionárias" a fim de pressionar por taxas de juros mais altas.

Ora, contando com essa subserviência ou comprometimento das autoridades do $\mathrm{BC}$, os cartéis financeiros, mesmo diante de uma situação de grande liquidez internacional, chantageiam para manter os juros altos no Brasil. Como esse comportamento das autoridades do BC no Brasil é mais ou menos atávico, já durando décadas, salvo alguns intervalos, os cartéis financeiros tanto internos como internacionais acostumaram-se a grandes ganhos aqui, ou seja, a elevadas taxas de juros. Assim, mesmo havendo bastante espaço para reduzi-las, ainda dentro de seus critérios, eles agem no sentido de impedir isso. Uma eventual fuga de capitais diante de uma queda dos juros não responderia, portanto, a qualquer mecanismo de mercado, mas à chantagem resultante desse poder monopólico dos cartéis financeiros. E só há uma maneira de bloquear essa chantagem: colocando à frente do Banco Central pessoas mais comprometidas com o País e, a partir daí, centralizando o câmbio nessa instituição. Aí, então, o BC poderia controlar o fluxo cambial de acordo com as necessidades da economia nacional, evitando grandes flutuações da taxa de câmbio, a fuga de capitais e os eventuais ataques especulativos contra nossa moeda ${ }^{10}$. E, com base nessa nova realidade, o BC poderia estabelecer uma taxa de câmbio ${ }^{11}$ e uma taxa básica de juros a partir da realidade e das necessidades internas da economia brasileira, e não mais com 
base nos "critérios internacionais", isto é, no interesse da banca internacional ${ }^{12}$. Todos os países que seguiram esse caminho puderam baixar radicalmente suas taxas de juros, e voltaram a crescer. Os exemplos mais recentes são os da Venezuela e Argentina. Mais ainda, segundo estudo do FMI, de 25 países que voltaram a crescer depois das crises cambiais dos anos 1990, 19 haviam feito alguma forma de reestruturação de suas dívidas.

\section{Financiamento do BNDES insuficiente}

O fato de o BC manter elevados os juros básicos, e, assim, bloquear o uso do principal instrumento que viabiliza o investimento, não significa que o governo Lula não tenha feito nada para melhorar o nível desse investimento. O BNDES, que, historicamente, tem sido o principal instrumento governamental destinado a financiar o investimento de longo prazo - salvo no período $\mathrm{FH}$, em que foi usado para emprestar dinheiro a grupos estrangeiros interessados na aquisição de empresas estatais -, teve um recorde de empréstimo em 2004: contratou um montante de $\mathrm{R} \$ 40$ bilhões, 14,3\% acima dos R\$ 35 bilhões de 2003 (Folha Online Dinheiro, 2005c). Além disso, por decisão do Conselho Monetário Nacional - que, por contar com a participação de outros ministros, não é inteiramente comandado pela equipe do Ministério da Fazenda -, a TJLP ${ }^{13}$ manteve-se em 9,75\% ao ano de abril de 2004 até fins de 2005, o que significava, nos níveis de inflação daquele ano, uma taxa real em torno de $2 \%$, apesar do aumento desde setembro da taxa selic e das demais taxas de juro da economia.

No entanto, além de não haver emprestado todo o valor previsto pelo próprio banco, que era de R\$ 47 bilhões, não atendeu nem de longe à demanda realizada pelas empresas através de cartas-consulta. $\mathrm{O}$ montante total demandado foi de R $\$ 98,4$ bilhões, e desse valor o próprio banco conseguiu enquadrar em suas normas a cifra de R\$ 75 bilhões (Folha Online Dinheiro, 2005c). Assim, emprestaram-se apenas $40,65 \%$ do montante demandado - isto é, das necessidades de financiamento de longo prazo expressas pelos investidores - e 53,33\% do montante aprovado pelo banco. Segundo o BNDES, esse valor solicitado indica "a dis- posição do empresariado em fazer investimentos produtivos, funcionando como um indicativo do nível de confiança no futuro econômico do país" (Folha Online Dinheiro, 2005c).

Mas, se dependesse do comando do Ministério da Fazenda e do Banco Central, nem isso o BNDES teria conseguido fazer. No segundo semestre de 2004, o presidente do BC, Henrique Meirelles, acusou o BNDES de ser responsável pelos elevados spreads ${ }^{14}$ do sistema financeiro no Brasil. Para ele, o fato de o banco emprestar diretamente aos tomadores finais a taxas de juro baixas, em lugar de repassar esse dinheiro barato por meio do sistema bancário, pressionaria os bancos comerciais a elevar seu spread. Esconde com essa afirmação o fato de que a grande margem bancária existente no Brasil se deve, no fundamental, ao elevado grau de concentração e, portanto, de monopolização do setor bancário, o que lhe dá condição de fixar os juros finais. Escamoteia, além disso, o fato de que o repasse do recurso barato aos bancos privados em nada garante, como nunca garantiu, que o destino final seja o investimento de longo prazo. Os bancos tem mil e uma artimanhas para desviar o recurso da finalidade estabelecida para o ganho fácil da especulação $^{15}$. A direção do BNDES, então liderada pelos professores Carlos Lessa e Darc Costa, respondeu à altura, denunciando o objetivo de Meirelles, que era fortalecer os bancos privados em detrimento do banco oficial, e terminou sendo demitida pelo governo.

Foi então nomeada para o BNDES uma equipe mais afinada com o grupo que então ocupava o Ministério da Fazenda, encabeçada pelo ex-ministro do Planejamento, o economista Guido Mantega ${ }^{16}$, e os tecnocratas da equipe econômica aproveitaramse desse fato para fazer nova carga sobre a política creditícia do banco. No começo de 2005, o secretário do Tesouro do Ministério da Fazenda, Joaquim Levy, propôs que a TJLP fosse atrelada à taxa selic, o que significava, na prática, que ela também passasse a subir. Ou seja, queria extinguir um dos poucos instrumentos que o governo Lula vem utilizando para viabilizar o investimento de longo prazo. Como disse o ministro do Desenvolvimento, Luiz Fernando Furlan: "E se vamos matar a única fonte de curto prazo, vamos 
comprometer nosso futuro" (Hora do Povo, 2005, p.2). Felizmente, Mantega, apesar de sua afinidade recente com a equipe da $\mathrm{Fa}-$ zenda, reagiu à altura, dizendo não aceitar qualquer possibilidade de realizar essa vinculação entre as duas taxas. É mais um ponto de tensão dentro do governo. E arrematou: Levy "não enxerga alguns palmos além do nariz" (Hora do Povo, 2005, p.2).

Os tecnocratas da Fazenda e do BC não conseguiram atrelar a TJLP à selic. Porém, têm logrado impedir que sua taxa nominal diminua com a queda da taxa de inflação, forçando, assim, de maneira indireta, a elevação de sua taxa real. Como a tendência é o IPCA ficar em 2005 abaixo dos $5 \%$ estabelecidos pela "meta de inflação", a permanência da TJLP em 9,75\% pode implicar numa taxa real em torno de $5 \%$, duas vezes e meia maior do que a que vigorou em 2004. Se o indexador utilizado for o IGP-M - que ficou pouco acima de 1\% em 2005 -, essa taxa real se aproximou dos $9 \%$, uma verdadeira taxa de agiotagem na esfera do financiamento do investimento produtivo.

O aporte do BNDES é muito importante para alavancar o investimento, principalmente quando cobra juros compatíveis com a atividade econômica. Mas, obviamente, a parcela mais importante de recursos destinados aos investimentos, tanto nas empresas privadas quanto nas estatais, são os recursos próprios oriundos de seus lucros. No ano passado, por exemplo, o montante total dos investimentos foi de cerca de $\mathrm{R} \$ 346,2$ bilhões $^{17}$. Como o BNDES financiou apenas $\mathrm{R} \$ 40$ bilhões e o investimento orçamentário da União sequer alcançou os 3\% do investimento total ${ }^{18}$, coube às próprias empresas públicas e privadas aportarem praticamente o conjunto dos restantes $\mathrm{R} \$ 306$ bilhões $^{19}$. Vimos que outros R $\$ 63,75$ bilhões de poupança deixaram de ser investidos, sendo drenados para o exterior ou para a especulação financeira. Vimos também que o nível de investimento realizado $(19,6 \%$ do PIB em 2004) é muito baixo para garantir a retomada auto-sustentada do crescimento da economia, na medida em que parte significativa desse investimento destina-se a repor a depreciação do capital fixo.

Pode-se alegar que a taxa selic, que baliza os demais juros praticados na econo- mia - à exceção da TJLP -, não afeta em nada o investimento produtivo ${ }^{20}$, na medida em que os bancos privados sediados no País não realizam empréstimo de longo prazo, destinando seus recursos apenas para títulos públicos e capital de giro das empresas. É mais uma falácia, que indica má-fé ou desconhecimento da realidade. O elemento básico, tanto para as empresas públicas e privadas quanto para o próprio governo decidirem o nível de investimento que farão com os recursos disponíveis, é a taxa básica de juros a selic -, e não a TJLP do BNDES. Por razões óbvias: o governo, porque o nível da sua "poupança" disponível para investimento depende dos encargos financeiros com que tem de arcar, e estes dependem da incidência da selic sobre a dívida pública; e as empresas, porque vão decidir o que fazer com seus lucros, se os investem na produção ou se os aplicam no mercado financeiro, a depender da taxa básica de juros, que baliza suas aplicações financeiras.

Portanto, uma baixa TJLP real, como a que foi praticada em 2004, é importante para viabilizar o investimento, mas é insuficiente para levá-lo para o nível adequado à retomada sustentada do crescimento. Mais uma vez, deparamo-nos com a necessidade de uma política monetária que seja centrada no longo prazo do investimento produtivo e do crescimento econômico auto-sustentado. O curto prazo do combate inflacionário ou do refinanciamento da dívida pública deve subordinar-se a essa lógica de longo prazo. Ou seja, devem-se buscar caminhos de combate à inflação ou de enfrentamento da dívida que não comprometam o crescimento sustentado do investimento produtivo e a melhoria crescente do bem-estar da população, bases do crescimento econômico auto-sustentado.

Recentemente, a equipe econômica, sobretudo nas palavras de Henrique Meirelles, em mais uma defesa dessa política monetária que escorcha o setor produtivo em benefício do sistema financeiro, alegou que o problema da economia não é a taxa básica de juros, mas as taxas finais, de aplicação, praticadas pelos bancos. Ora, é evidente que a atividade produtiva é, em grande medida, afetada por essas taxas finais, já que são elas que balizam o compor- 
tamento de empresas e consumidores. Mas, também é evidente que essas taxas finais, como assinalamos antes, são condicionadas em última instância, ainda que não exclusivamente, pela taxa básica. Segundo Meirelles, essas taxas finais são elevadas porque o spread bancário também o é. Porém, diz ele que a responsabilidade disso não seria dos bancos, mas, sim, do BNDES, que não lhes estaria repassando recursos baratos para emprestarem ao tomador final, e dos clientes, que não pagariam corretamente suas dívidas. Quanto ao BNDES, já vimos que a proposta de Meirelles é repassar os recursos do banco através dos bancos privados.

Vejamos o outro argumento, o da inadimplência. Alegam Meirelles \& Cia. que a elevada inadimplência seria a responsável por um elevado "risco bancário", o que estaria levando os bancos, para compensá-lo, a elevar o spread bancário e, por conseguinte, a cobrar juros finais elevados. Ora, os bancos estão nadando em dinheiro. A taxa média de rentabilidade deles esteve em um patamar em torno 15\% de 1995 a 2002 e cresceu mais ainda de 2003 para cá, superando em várias vezes a rentabilidade do setor nãofinanceiro ${ }^{21}$. Se esse risco fosse tão grande como se apregoa, sua rentabilidade seria menor que a média do País, ou mesmo estariam tendo prejuízo. Beira, então, ao cinismo alegar excesso de "risco bancário". Existe excesso, sim, de vontade de lucupletar-se da renda nacional, e excesso de vontade em servir aos bancos.

Assim, para diminuir um risco bancário inexistente, o governo bancou a aprovação pelo Congresso de um projeto de lei de falência - designado de Lei de Recuperação de Empresas - que dormia na casa legislativa há já bastante tempo. O projeto tem dois aspectos básicos: 1) cria a figura da chamada recuperação judicial, que supostamente favoreceria a recuperação das empresas em dificuldade ${ }^{22}$; 2) prioriza o pagamento dos débitos bancários no caso de falência. Detenhamo-nos neste segundo aspecto, que tem supostamente a ver com a questão dos juros. Antes, a prioridade era dos débitos trabalhistas e tributários; só depois, viriam os débitos bancários. A forma como a nova lei foi aprovada na Câmara invertia essa situação dando prioridade aos débitos bancários. $\mathrm{O}$
Senado amenizou um pouco essa decisão: estabeleceu que os débitos trabalhistas terão prioridade até 150 salários mínimos (ou $\mathrm{R} \$$ 39 mil ao nível da época da aprovação da lei, no começo de 2005); a partir daí, a prioridade passa para os débitos bancários e só então vêm os débitos tributários. Ou seja, são prejudicados os trabalhadores e a sociedade (tributos) para beneficiar os bancos.

Alega a equipe econômica que, assim, diminui o risco dos bancos, levando-os a reduzir sua margem e, por conseguinte, as taxas finais de juros. A primeira reação da Federação Brasileira de Bancos (Febraban) foi declarar que não se deve esperar uma queda dos juros tão cedo; que isso só poderia ocorrer no longo prazo. Como a longo prazo todos estaremos mortos, como dizia Keynes, a entidade dos bancos estava com isso querendo dizer que os mesmos deverão usar essa vantagem, não para baixar os juros, mas para apropriar-se de recursos que, originalmente, seriam trabalhistas ou públicos. É a mais completa subordinação do País aos interesses dos bancos. Essa mudança de legislação não passa de mais uma ilusão que as autoridades econômicas tentam incutir na opinião pública, pois deixam de considerar que a razão fundamental para as elevadas margens bancárias é o comportamento de cartel que, em face do elevado grau de concentração/centralização do setor, os bancos assumem no País ${ }^{23}$. Não havendo livre concorrência no setor bancário, a redução do risco não implica em redução do preço do dinheiro, mas no aumento do ganho do setor financeiro.

\section{Conclusão}

Demonstramos neste artigo que a retomada do crescimento de uma economia costuma se dá pela ocupação de capacidade ociosa gerada no período de crise ou estagnação. A continuidade desse crescimento e sua transformação em crescimento autosustentado depende, no entanto, do aumento da capacidade produtiva gerada pelo incremento do nível de investimentos.

A realização dos novos investimentos depende, certamente, do nível de poupança da economia, da lucratividade das empresas ou da capacidade de financiamento dos 
órgãos voltados ao financiamento de longo prazo, como o BNDES. No entanto, a canalização da poupança nacional, do lucro empresarial ou dos financiamentos para o investimento depende, fundamentalmente, do nível da taxa de juros. E não apenas das taxas de longo prazo, mas, sobretudo, da taxa básica de juros, já que esta condiciona não apenas o comportamento do conjunto das taxas de juros, mas também a disposição dos empresários de usar ou não seus recursos no investimento produtivo.
Demonstramos, também, que as alegações apresentadas pelas autoridades monetárias do País para manter elevada a taxa básica real de juros não se sustentam, porque, de um lado, a inflação vem declinando sistematicamente nos últimos anos e, de outro, não está ameaçada a capacidade de auto-financiamento da dívida pública brasileira, na medida que os juros internacionais estão bem mais reduzidos do que os praticados no Brasil.

Tabela

Taxa de investimento (FBCF/PIB - \%) - 1995-2004

\begin{tabular}{|l|l|l|l|l|l|l|l|l|l|}
\hline 1995 & 1996 & 1997 & 1998 & 1999 & 2000 & 2001 & 2002 & 2003 & 2004 \\
\hline 20,5 & 19,3 & 19,9 & 19,7 & 18,9 & 18,9 & 19,5 & 18,3 & $18,05^{*}$ & 19,6 \\
\hline
\end{tabular}
Fonte: IBGE
* Há também estimativas que variam de $17,1 \%$ e $17,8 \%$.

\section{Notas}

${ }^{1}$ No primeiro semestre, a taxa de poupança fora de 24,15\% (Fonte: IBGE. Extraído de Folha Online, 2005a)

${ }^{2}$ A diferença entre um volume de poupança de R\$ 409,95 bilhões e um volume de investimento de $\mathrm{R} \$$ 346,2 bilhões (Fonte: IBGE. Extraído de Folha Online Dinheiro, 2005a.). O PIB de 2004 foi de R \$1,769 trilhão (fonte: IBGE. Extraído de Folha Online Dinheiro, 2005a).

${ }^{3}$ Média aritmética das taxas anuais de crescimento do PIB na década.

${ }^{4}$ A taxa média de rentabilidade sobre o patrimônio das 500 maiores empresas não-financeiras, que fora de $11,15 \%$ na década de 80 , não passou de $3 \%$ nos oito anos da era FH (ver "Melhores e maiores", Revista Exame, 1999: 12; jul. 2003: 22). Nesse último período, a taxa de rentabilidade dos bancos esteve em torno de $15 \%$.

${ }^{5}$ Em 2002, quando, segundo levantamento da consultoria Austin Asis junto aos 50 maiores bancos do País, estes apresentaram uma taxa de rentabilidade de $24,5 \%$, as empresas não-financeiras, que antes de pagarem os encargos financeiros, apresentavam uma rentabilidade de $12 \%$ sobre seu patrimônio, viram essa rentabilidade transformar-se num prejuízo de 13,1\%, depois dos encargos. Segundo a Associação Nacional de Executivos de Finanças, Administração e Contabilidade (ANEFAC), o aumento dos juros naquele ano fez com que a parcela da receita das empresas comprometida com juros tenha aumentado de 7,2\% para 13,7\% (Cf. Souza, 2004: 699-700).

${ }^{6}$ Medida pelo IPCA do IBGE, baixou de $12,58 \%$ em 2002 para $9,33 \%$ em $2003,7,57 \%$ em 2004 e $5,88 \%$ em 2005 (Fonte: IBGE), e os próprios agentes financeiros, que têm interesse em projetar uma taxa mais alta a fim de forçar uma elevação dos juros, "esperam", de acordo com as últimas "pesquisas Focus" divulgadas pelo BC, uma taxa de 4,5\% para 2006 (Fonte: Banco Central). Além disso, o IGP-DI anual tem estado um pouco acima de $1 \%$.

${ }^{7}$ A partir de setembro de 2005, o COPOM começou a baixa moderadamente a taxa selic nominal, mas, como a inflação está em baixa, a taxa real de juros permanece praticamente inalterada.

${ }^{8}$ Ver nota anterior.

${ }^{9}$ Houve um forte processo de fusão bancária nos anos 90 a nível mundial. Na principal praça financeira do mundo, os EUA, entre 1996 e abril de 1998, das nove maiores fusões ocorridas, três ocorreram no setor financeiro. É importante registrar que ocorreu naquela década o maior processo de fusões da história do País: o conjunto das transações para fusões subiu de US\$ 138 bilhões em 1991 (2\% do PIB) para US\$ 957 bilhões em 1997 (12\% do PIB). (Cf. Souza, 2001: 128).

${ }^{10}$ A queda de braço entre o governo argentino e seus credores a propósito da renegociação de sua dívida externa, que estava em moratória, revelou que, quando um governo nacional age com determinação, é capaz de dobrar a resistência da banca internacional: a Argentina conseguiu que $76 \%$ de sua dívida em moratória fosse renegociada com até $75 \%$ de desconto. Segundo informou o ministro da Economia, Roberto Lavagna, a dívida de US\$ 102 bilhões foi reduzida para US\$ 35 bilhões, economizando, assim, US\$ 67 bilhões.

${ }^{11} \mathrm{O}$ chamado câmbio flutuante significa, na prática, deixar uma variável fundamental da economia - na medida em que interfere no volume do comércio exterior e, portanto, na atividade econômica e no nível do emprego - nas mãos dos especuladores com moeda. O mais correto seria o controle cambial, isto 
é, a adoção de um sistema de câmbio administrado, através do qual o BC administraria a taxa de câmbio de acordo com as metas de exportação e importação do País.

12 Tem razão o economista Paulo Nogueira Batista Jr., ao afirmar: "E fica cada vez mais claro que precisamos de uma reforma no Banco Central capaz de transformá-lo em uma instituição orientada pelo interesse nacional" (Cf. Baptista Jr., 2005).

${ }^{13}$ Taxa de Juros de Longo Prazo, que baliza os empréstimos do BNDES.

${ }^{14}$ Diferença entre a taxa de captação e a taxa de aplicação do sistema bancário.

${ }^{15} \mathrm{O}$ recente escândalo do Banco Santos, acusado, dentre outras coisas, de praticar uma gigantesca fraude com recursos do BNDES, é apenas a ponta do iceberg dessa verdadeira torrente de recursos desviados do banco oficial. Empresários ouvidos pela Polícia Federal acusam o dono do Banco Santo de exigir que metade dos recursos do BNDES que conseguem emprestado por seu intermédio fosse depositada em conta por ele indicada.

${ }^{16}$ No início do governo, à frente do Ministério do Planejamento, Mantega apresentava certas divergências com o grupo da Fazenda, liderado por Palocci, sobretudo no que tange ao aperto monetário e fiscal, mas também porque propugnava uma política industrial ativa, com base no consumo de massas e nas tecnologias de ponta, enquanto o grupo de Palocci prefere deixar o desenvolvimento industrial ao sabor do "mercado", isto é, da lógica dos cartéis. No entanto, com o passar do tempo, Mantega foi-se amoldando à política praticada pelo Fazenda e o Banco Central - pelo menos publicamente.

${ }^{17}$ Considerando uma taxa de investimento de $19,6 \%$ e um PIB de R \$1,769 trilhão (Fonte: IBGE. Dados extraídos de Folha Online Dinheiro, 2005a)

${ }^{18}$ Em 2004, apesar da previsão orçamentária de que o conjunto das despesas de capital, mais os créditos suplementares aprovados, deveria atingir o montante de R\$12,37 bilhões, a execução orçamentária mal chegou a R\$ 9,16 bilhões, um percentual de 2,65\% do investimento total no País (Ministério da Fazenda. Tesouro Nacional, 2005). Em 2003, de um total orçado (inclusive créditos) de $\mathrm{R} \$ 16,95$ bilhões, só se investiram R\$ 6,45 bilhões (Ministério do Planejamento, 2005). Os próceres do Ministério da Fazenda fizeram festa quando, no dia 21 de fevereiro de 2005, o FMI anunciou sua concordância com a proposta do governo de usar parte do superávit primário "para investimentos em infra-estrutura e outros projetos de investimento público com retorno macroeconômico e fiscal potencialmente forte a médio prazo, consistente com uma posição de sólida sustentabilidade fiscal" ("Comunicado da diretora do Departamento de Assuntos Fiscais do FMI", 2005). Pelo barulho feito, até parecia que rios de dinheiro estariam disponíveis para investimento, mas não passavam "de US\$ 1 bilhão ao ano pelos próximos três anos (2005-2007)" (Ibid.), isto é, cerca de R\$2,7 bilhões, à taxa de câmbio atual - não mais que irrisórios 3,25\% do superávit primário gerado em 2004.

${ }^{19} \mathrm{O}$ governo de Lula está entusiasmado com o microcrédito. É importante estimular essa modalidade de financiamento, na medida em que favorece as micro e pequenas empresas. Mas, obviamente, o montante do financiamento daí derivado não passa de um grão de areia na montanha de necessidades de recursos para investimento no País: segundo o Ministério da Fazenda, “a carteira ativa dessas operações, em 30/ 09/2004, considerando apenas cinco grandes instituições financeiras, situava-se em R\$ 339 milhões e 691.536 operações. O acumulado em um ano nestes mesmos cinco bancos chega a 2 milhões de contratos e R\$ 843 milhões emprestados". (Ministério da Fazenda, dez. 2004: 62). Esse volume anual não passa de $2 \%$ do volume emprestado pelo BNDES em 2004 e de $0,5 \%$ do volume de crédito que, em dezembro de 2004, constava nas carteiras dos bancos como empréstimos às empresas ( $\mathrm{R} \$ 158,3$ bilhões. Fonte: Global Invest).

${ }^{20}$ Veja a pérola de declaração do secretário-executivo do Tesouro Nacional, Joaquim Levy: “Um juro que aumente para garantir a consistência macroeconômica não mata o investimento" (Folha de S.Paulo, 2005: B4).

${ }^{21}$ Em 2004, segundo a consultoria Economática, o lucro líquido do setor bancário no Brasil foi de R\$13,96 bilhões, R \$ 1,39 bilhão a mais do que no ano de 2003, que já havia sido considerado recorde ("Setor bancário é o mais lucrativo, diz Economática", 2005). Esse movimento prosseguiu em 2005: no primeiro trimestre do ano, os quatro maiores bancos (Banco do Brasil, Bradesco, Itaú, Unibanco) obtiveram um lucro de $\mathrm{R}$ \$ 3,71 bilhões, o dobro de igual período de 2004 (CARNEIRO, 2005).

${ }^{22}$ Estima-se que hoje cerca de $80 \%$ das empresas em concordata, em lugar de serem recuperadas, chegam fatalmente à falência.

23 “No setor bancário, segundo estudo da consultoria Austin Asis, as maiores instituições aumentaram seu peso de 45,2\% dos ativos totais do sistema em 1994 para 60,2\% em 2002" (SOUZA, 2004, p.697).

\section{Referências}

BAPTISTA JR., Paulo Nogueira. “Estatizando o Banco Central". Revista Carta Maior. Disponível em: <http:/ / agenciacartamaior.uol.com.br/agencia>. Acesso em: 24.03.2005.

“BNDES tem recorde de empréstimos, mas sobram R\$ 7 bi no caixa em 2004". Folha Online - Dinheiro. Acesso em: 13.01.2005, 11h46m.

CARNEIRO, Mariana. “Bancos ganham nas duas pontas". Disponível em: <http://jbonline.terra. com.br>. Acesso em: 28.05.2005.

"Comunicado da diretora do Departamento de Assuntos Fiscais do FMI". In: Folha Online - Dinheiro. Disponível em: <http://www1.uol.com.br/folha/ dinheiro>. Acesso em: 22.02.2005, 16h06m.

Evolução da execução financeira do governo central em 2004. Disponível em: <www.fazenda.gov.br>. Acesso em: 30.04.2005, 19h10m.

Folha de S.Paulo, 18.03.2005.

Folha Online Dinheiro. “PIB brasileiro somou R \$ 1,769 trilhão em 2004, diz IBGE". Disponível em: <http:// www1.folha.uol.com.br/folha/dinheiro>. Acesso em: 31.03.2005a, 09h32m. 
Folha Online Dinheiro. "Taxa de investimento na economia tem o melhor resultado desde 1998". Disponível em: <http://www1.folha.uol.com.br/ folha/dinheiro>. Acesso em: 31.03.2005b, 09h45m.

Folha Online Dinheiro. Disponível em: <http:// www1.folha.uol.com.br/folha/dinheiro>. Acesso em: 13.01.2005c, $11 \mathrm{~h} 46 \mathrm{~m}$.

Hora do Povo, 18-22.02.2005.

IBGE. Pesquisa industrial mensal mensal produção física Brasil - produção industrial cai 2,\% em setembro. Disponível em: <http:/ / www.ibge.gov.br>. Acesso em: 08.11.2005.

“Melhores e maiores", Revista Exame, 1999.

“Melhores e maiores", Revista Exame, jul. 2003.

Ministério da Fazenda. Política econômica e reformas estruturais. Brasília, abr. 2003.

Ministério da Fazenda. Tesouro Nacional. Evolução da execução financeira do governo central em 2004. Disponível em: <www.fazenda.gov.br>. Acesso em: 30.04.2005, 19h10m.

Ministério do Planejamento. Disponível em: <http:/ / www.planejamento.gov.br>. Acesso em: 13.03.2005, $13 \mathrm{~h} 33 \mathrm{~m}$.

"Setor bancário é o mais lucrativo, diz Economática". Disponível em <http://noticias.uol.com.br/ economia>. Acesso em: 05.04.2005, às 17,23h

Souza, Nilson Araújo de. A longa agonia da dependência economia brasileira contemporânea (JK/FH). São Paulo: AlfaOmega, 2004.

Souza, Nilson. Ascensão e queda do império americano. São Paulo: Ed. CPC-UMES/Mandacaru, 2001.

UOL - Últimas Notícias. Disponível em: <http:// notícias.uol.com.br/economia/ultnot/reuters $>$. Acesso em: 01.03.2005, 10h38m. 